\title{
Changes in the Total Polyphenolic Content and Antioxidant Capacities of Perilla (Perilla frutescens L.) Plant Extracts during the Growth Cycle
}

\author{
Francesco Gai, ${ }^{1}$ Pier Giorgio Peiretti, ${ }^{1}$ Magdalena Karamać, ${ }^{2}$ and Ryszard Amarowicz ${ }^{2}$ \\ ${ }^{1}$ National Research Council, Institute of Science of Food Production, 10095 Grugliasco, Italy \\ ${ }^{2}$ Institute of Animal Reproduction and Food Research, Polish Academy of Sciences, 10-747 Olsztyn, Poland \\ Correspondence should be addressed to Ryszard Amarowicz; r.amarowicz@pan.olsztyn.pl
}

Received 7 February 2017; Accepted 9 April 2017; Published 8 May 2017

Academic Editor: Raul Ferrer-Gallego

Copyright ( $\odot 2017$ Francesco Gai et al. This is an open access article distributed under the Creative Commons Attribution License, which permits unrestricted use, distribution, and reproduction in any medium, provided the original work is properly cited.

Changes in the total polyphenolics and antioxidative capacity of the perilla (Perilla frutescens L.) plant, during the growth cycle, have been analyzed in this study. These parameters were evaluated at five morphological stages. The extracts characterized by the highest total phenolic compound content were obtained at the full flowering stage. The phenolic compound profile was characterized by the presence of three major compounds, with rosmarinic acid being the most abundant. Moreover, their contents were significantly different according to the growth stage. High Trolox equivalent antioxidant capacity values were found for the last two growth stages. The lowest ferric-reducing antioxidant power value was observed for the medium vegetative stage. The highest antiradical activity against $\mathrm{DPPH}^{*}$ was observed for extracts obtained from the early vegetative stage. The antioxidant activity changes during the growth cycle, and this change may be useful to determine the optimal harvest time.

\section{Introduction}

Perilla (Perilla frutescens L.), which belongs to the Lamiaceae family, is a native plant to Asian countries, such as Korea, Japan, and China, and it has traditionally been used as a source of human and animal food [1] that is rich in fat [2-4] and good quality protein [5]. Consumption of perilla seeds or oil in humans has been reported without any adverse effects [6]. The positive effect of perilla seeds fed in term on the fatty acids composition in the muscle and lipid tissue was reported for pig [7] and in rabbits [8]. Perilla seeds are a rich source of $\alpha$-linolenic acid (approx. 60\%), as well as phenolic compounds (flavones, cyanidins, and phenolic acids), sterols, and terpenoids $[9,10]$. Bioactive compounds of perilla exhibit antiseptic, antimicrobial, anticarcinogenic, antiinflammatory, antipyretic, and immunomodulatory properties [11-20]. Moreover, perilla leaf extracts have shown antimutagenic, antiproliferative, and antioxidative activities, as well as neuroprotective effects [21-26]. However, few studies have focused on the isolation, characterization, and identification of perilla phenolic antioxidants $[27,28]$ which are known to be able to protect human organism against free radicals and reactive oxygen species and can retard the progress of many chronic diseases as well as lipid autoxidation in foods [29-31]. Chou et al. [32] examined water extracts from different anatomical parts of Perilla frutescens in order to establish their antioxidant activities and phenolic compounds and found that stem extracts had the highest DPPH free radical activity and the highest superoxide anion radical scavenging activity. The content of total flavonoids and phenolics of the stem extracts were found to be higher than those of other plant extracts. Peiretti [33] determined the proximate chemical composition, fatty acid composition, and gross energy content of perilla plants during the growth cycle. However, no study has been carried out so far regarding the antioxidant activities of the aerial part of perilla harvested at different growth stages. The aim of this study was to determine the phenolic compounds and antioxidant potential of perilla extracts during the growth cycle. 
TABLE 1: Total phenolic contents of the perilla extract and fresh matter (FM) at different growth stages.

\begin{tabular}{lccrc}
\hline Growth stage & $\begin{array}{c}\text { Plant height } \\
(\mathrm{cm})\end{array}$ & $\begin{array}{c}\text { Yield of extraction } \\
(\%)\end{array}$ & 3.09 & \multicolumn{2}{c}{ Total phenolics } \\
& 15 & 2.52 & $100.0 \pm 11.1^{\mathrm{a}}$ & $3.09 \pm 0.34^{\mathrm{ab}}$ \\
\hline Early vegetative & 30 & 2.20 & $54.3 \pm 5.9^{\mathrm{b}}$ & $1.37 \pm 0.15^{\mathrm{c}}$ \\
Medium vegetative & 40 & 2.31 & $61.4 \pm 7.8^{\mathrm{b}}$ & $1.35 \pm 0.17^{\mathrm{c}}$ \\
Late vegetative & 60 & 3.26 & $118.2 \pm 12.0^{\mathrm{a}}$ & $2.73 \pm 0.27^{\mathrm{b}}$ \\
Early flowering & 70 & $123.2 \pm 12.7^{\mathrm{a}}$ & $4.02 \pm 0.42^{\mathrm{a}}$ \\
Full flowering & & &
\end{tabular}

Means with the same letter are not significantly different $(P<0.05)$.

\section{Materials and Methods}

2.1. Plant Material and Environmental Conditions. The biological experiment was conducted in the Western Po Valley near Cuneo, North West Italy (longitude $7^{\circ} \mathrm{E}$, latitude $44^{\circ} \mathrm{N}$ ). Perilla seeds, purchased from the Manitoba Seed Expert of Manitoba Inc. (Winnipeg, Canada), were sown in May. No irrigations or fertilisers were applied after sowing. Herbage samples were collected from June to July, using edging shears $(0.1 \mathrm{~m}$ cutting width), from the early vegetative (plant height $15 \mathrm{~cm}$ ) to the full flowering stage (plant height $70 \mathrm{~cm}$ ), from randomly located $2 \mathrm{~m}^{2}$ subplots in $3 \times 8 \mathrm{~m}^{2}$ plots, with three replicates cut to a 1 to $2 \mathrm{~cm}$ stubble height. Fresh samples of the whole plants were immediately frozen, using a laboratory lyophilizer (5 Pascal, Trezzano sul Naviglio, Italy), and were then freeze-dried and ground to pass a $1 \mathrm{~mm}$ screen.

2.2. Chemicals. Sodium persulfate, ferrous chloride, the Folin-Ciocalteu phenol reagent, 2,2'-azinobis-(3-ethylbenzothiazoline-6-sulfonic acid) (ABTS), 2,2' -diphenyl-1-picrylhydrazyl (DPPH), 2,4,6-tri(2-pyridyl)-s-triazine (TPTZ), 6-hydroxy-2,5,7,8-tetramethyl-chroman-2-carboxylic acid (Trolox), (+)-catechin, rosmarinic acid, and apigenin were purchased from Sigma (Poznań, Poland). Acetonitrile, trifluoroacetic acid, and methanol were obtained from the P.O.Ch. Company (Gliwice, Poland).

2.3. Extraction. The phenolic compounds were then extracted from ground plants using $80 \%(\mathrm{v} / \mathrm{v})$ methanol, as described by Amarowicz and Raab [34]; methanol was evaporated in a rotary evaporator (Büchi Labortechnik AG, Flawil, Switzerland) and the remaining aqueous solution was lyophilized.

2.4. Determination of the Total Phenolic Content. The TPC of the extracts was determined using Folin-Ciocalteu's phenol reagent [35]. The results were expressed as $\mathrm{mg}$ catechin equivalent per g extract or plant fresh matter (FM).

2.5. Trolox Equivalent Antioxidant Capacity. The Trolox equivalent antioxidant capacity (TEAC) was determined using the Re et al. [36] method. The results were expressed as $\mu \mathrm{mol}$ Trolox equivalent per g extract or plant FM.

2.6. Ferric-Reducing Antioxidant Power. The ferric-reducing antioxidant power (FRAP) assay was performed, as described by Benzie and Strain [37]. The FRAP value was expressed as $\mu \mathrm{mol} \mathrm{Fe}{ }^{2+}$ equivalent per g extract, or plant $\mathrm{FM}$, using the $\mathrm{Fe}^{2+}$ calibration curve.

2.7. Scavenging of the DPPH Radical. The antiradical activity of the extracts against DPPH radical was determined as described in Amarowicz et al. [38].

2.8. HPLC Analysis. The phenolic compounds present in the extract were analyzed using a Shimadzu HPLC system (Shimadzu Corp., Kyoto, Japan), consisting of two LC-10AD pumps, an SCTL 10A system controller and an SPD-M 10A photodiode array detector, and a prepacked Luna C18 column ( $4 \times 250 \mathrm{~mm}, 5 \mu \mathrm{m}$; Phenomenex, Torrance, CA, USA). Elution was conducted at condition described by Peiretti et al. [39].

2.9. Statistical Analysis. All the biological experiments and chemical determinations were performed in triplicate. The results are reported as mean value \pm SD values. ANOVA and Duncan's test were performed at a $P<0.05$ level to evaluate the significance of differences among mean values.

\section{Results and Discussion}

3.1. Total Phenolic Contents. The TPC of the perilla plant extracts and of the fresh matter (FM) is reported in Table 1. The extracts were characterized by a significant difference between the stages $(P<0.05)$, with the highest TPC contents being observed for the early vegetative and for the early and full flowering stages (100, 118 and $123 \mathrm{mg}$ catechin eq./g extract, resp.). Similar statistical differences were found among the stages when TPC was expressed according to the plant FM, with the lowest content being found for the late vegetative stage ( $1.37 \mathrm{mg}$ catechin eq./g plant FM). The TPC results obtained in the present research are consistent with the values reported in the literature, even though some differences have emerged which might be due to the use of different phenolic compound standards or different extraction methods.

Deng et al. [40] investigated Perilla frutescens leaves and another 55 vegetables, and they determined the TPC in both lipophilic and hydrophilic extracts. The perilla leaves showed a TPC of 10.9 and $3.5 \mathrm{mg}$ gallic acid equivalent (GAE)/g in the lipophilic and hydrophilic fractions, respectively, for a total of $14.4 \mathrm{mg} \mathrm{GAE} / \mathrm{g}$. Li et al. (2013) determined the TPC of 
TABLE 2: Individual phenolic compounds in the perilla extracts at different growth stages.

\begin{tabular}{lcccc}
\hline Growth stage & Plant height $(\mathrm{cm})$ & \multicolumn{3}{c}{ Compounds $(\mathrm{mg} / \mathrm{g}$ extract) } \\
& & $1^{*}$ & $2^{*}$ & $3(\mathrm{rosmarinic}$ acid) \\
\hline Early vegetative & 15 & $15.31 \pm 1.65^{\mathrm{a}}$ & $4.44 \pm 0.42^{\mathrm{b}}$ & $57.93 \pm 3.05^{\mathrm{a}}$ \\
Medium vegetative & 30 & $9.71 \pm 1.27^{\mathrm{b}}$ & $2.72 \pm 0.27^{\mathrm{c}}$ & $26.44 \pm 2.06^{\mathrm{b}}$ \\
Late vegetative & 40 & $12.87 \pm 1.20^{\mathrm{ab}}$ & $5.92 \pm 0.71^{\mathrm{a}}$ & $56.89 \pm 2.79^{\mathrm{a}}$ \\
Early flowering & 60 & $10.42 \pm 0.53^{\mathrm{b}}$ & $6.46 \pm 0.58^{\mathrm{a}}$ & $66.17 \pm 4.90^{\mathrm{a}}$ \\
Full flowering & 70 & $10.54 \pm 0.94^{\mathrm{b}}$ & $6.14 \pm 0.72^{\mathrm{a}}$ & $55.12 \pm 5.09^{\mathrm{ab}}$ \\
\hline
\end{tabular}

*Expressed as apigenin; means with different letters in the same column are significantly different $(P<0.05)$. Numbers of compounds are connected with peak numbers in Figure 1.

TABLE 3: Individual phenolic compounds in the perilla fresh matter (FM) at different growth stages.

\begin{tabular}{lcccc}
\hline Growth stage & Plant height $(\mathrm{cm})$ & \multicolumn{2}{c}{ Compounds (mg/g FM) } \\
& & $1^{*}$ & $2^{*}$ & 3 (rosmarinic acid) \\
\hline Early vegetative & 15 & $0.472 \pm 0.051^{\mathrm{a}}$ & $0.137 \pm 0.013^{\mathrm{b}}$ & $1.784 \pm 0.094^{\mathrm{ab}}$ \\
Medium vegetative & 30 & $0.246 \pm 0.031^{\mathrm{c}}$ & $0.069 \pm 0.007^{\mathrm{c}}$ & $0.671 \pm 0.052^{\mathrm{d}}$ \\
Late vegetative & 40 & $0.287 \pm 0.017^{\mathrm{c}}$ & $0.124 \pm 0.015^{\mathrm{b}}$ & $1.195 \pm 0.059^{\mathrm{c}}$ \\
Early flowering & 60 & $0.240 \pm 0.013^{\mathrm{c}}$ & $0.149 \pm 0.013^{\mathrm{b}}$ & $1.521 \pm 0.113^{\mathrm{b}}$ \\
Full flowering & 70 & $0.348 \pm 0.030^{\mathrm{b}}$ & $0.203 \pm 0.024^{\mathrm{a}}$ & $1.815 \pm 0.170^{\mathrm{a}}$ \\
\hline
\end{tabular}

${ }^{*}$ Expressed as apigenin; means with different letters in the same column are significantly different $(P<0.05)$. Numbers of compounds are connected with peak numbers in Figure 1.

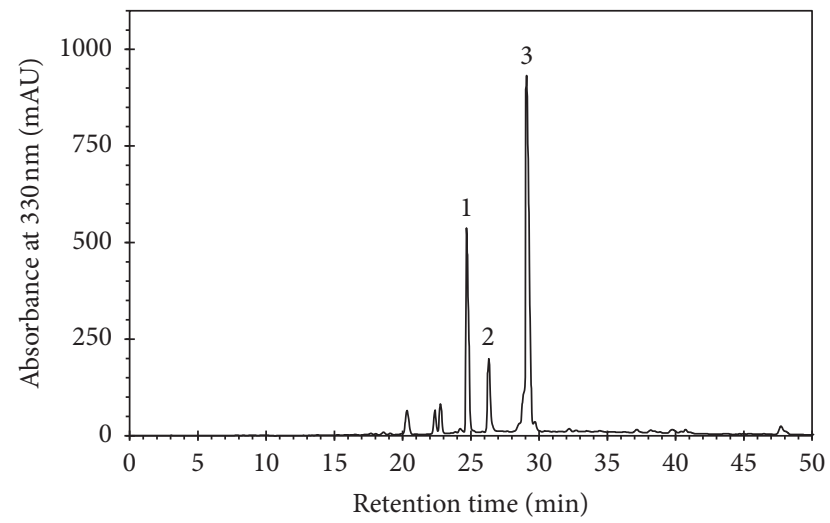

FIGURE 1: HPLC chromatogram of the phenolic compounds present in the perilla extract.

infusions from 223 medicinal plants, and among these they found $12.9,4.2$, and $5.2 \mathrm{mg} \mathrm{GAE} / \mathrm{g}$ for the seed, stem, and leaves of Perilla frutescens, respectively.

Saita et al. [41] determined the polyphenol concentration of two varieties of Perilla frutescens, var. crispa, and found that the TPC values were $4.6 \mathrm{mg} / \mathrm{mL}$ and $1.7 \mathrm{mg} / \mathrm{mL}$ in red and green perilla, respectively.

Hong et al. [27] evaluated the TPC levels of Perilla frutescens leaves extracted by means of various solvents $(70 \%$ ethanol, water, or methanol) and under different fractionation conditions ( $n$-hexane, chloroform, ethyl acetate, and $n$ butanol). A good TPC level, expressed as GAEs, was found in the ethyl acetate fraction $(227.38-373.92 \mathrm{mg} / \mathrm{g})$.

3.2. Individual Phenolic Compounds. The individual phenolic compounds contained in the perilla extracts were separated by means of HPLC, and the resulting chromatograms showed the presence of three major peaks (1-3), with retention times of 24.8, 26.3, and $29.5 \mathrm{~min}$ (Figure 1). The UV-DAD spectra of compounds 1,2 , and 3 were characterized by maxima at 266 and $334 \mathrm{~nm}$ (1), 280 and $334 \mathrm{~nm}$ (2), and $330 \mathrm{~nm}$ (3) and were very similar to the spectrum of apigenin and rosmarinic acid (Figure 2).

The individual phenolic compounds, quantified by means of HPLC analysis on the perilla plant extracts or FM, are reported in Tables 2 and 3, respectively. The contents of the individual phenolic compounds, in both the extract and the plant, differed significantly according to the growth stage.

Compound 3 was identified, on the basis of the UV spectrum and retention time of the standard, as rosmarinic acid. The results revealed that this compound was the most abundant phenolic constituent. Compound 3 contents in the extract ranged from 26.4 to $66.2 \mathrm{mg} / \mathrm{g}$ of extract, at the medium vegetative and early flowering stages, respectively. As far as the perilla FM data are concerned, the rosmarinic acid content ranged from 0.67 to $1.82 \mathrm{mg} / \mathrm{g}$ of plant $\mathrm{FM}$ at the medium vegetative and full flowering stage, respectively.

In the perilla extracts (Table 2), individual phenolic compounds 1 and 2 , expressed as apigenin equivalents, ranged from 9.7 to $15.3 \mathrm{mg} / \mathrm{g}$ of extract and from 2.7 to $6.5 \mathrm{mg} / \mathrm{g}$ of extract, respectively. In the perilla FM (Table 3 ), compound 1 ranged from 0.24 to $0.47 \mathrm{mg} / \mathrm{g}$ of plant $\mathrm{FM}$, while compound 2 ranged from 0.07 to $0.20 \mathrm{mg} / \mathrm{g}$ of plant $\mathrm{FM}$.

Jun et al. [42] investigated the antioxidant activities of various extracts from Perilla frutescens var. acuta leaves and, on the basis of HPLC analysis, found that rosmarinic acid was the most abundant phenolic acid in subfraction 3 of perilla leaves.

Zhu et al. [43], by means of the supramolecular technique and solvent extraction, identified, in Perilla frutescens leaf 

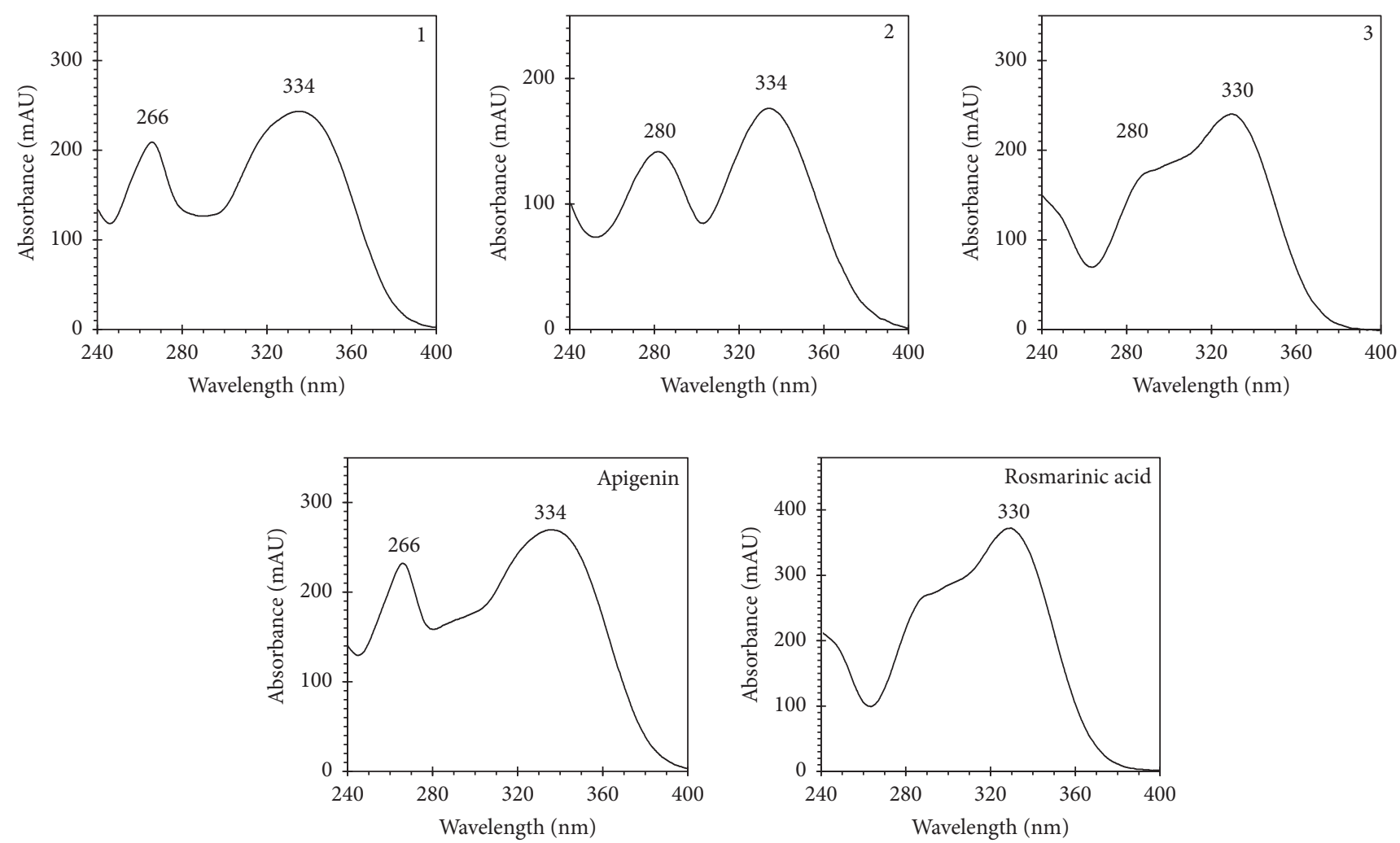

FIGURE 2: UV-DAD spectra of compounds 1-3 separated using HPLC.

extracts, phenolic acids (rosmarinic and caffeic acids) and flavonoids (glucuronides of luteolin and apigenin, shisonin, and malonylshisonin), and they found that rosmarinic acid was the most abundant phenolic compound.

Kang and Lee [44] investigated changes in the phenolic phytochemical contents in the leaves of Perilla frutescens, cv. Bora, for eight different harvest times over a period of two months. The profile was characterized by three phenolic acids (caffeic acid, rosmarinic acid, and rosmarinic acid methyl ester) and five anthocyanins methyl ester. These authors observed significant differences between the individual and total phytochemical contents, and the predominant constituent was rosmarinic acid. As far as the different harvest times are concerned, the lowest content was $39.0 \mathrm{mg} / \mathrm{g}$ on 17th of August (phenolic acid: $32.6 \mathrm{mg} / \mathrm{g}$ ), while the highest content was found on 21st of September, with $82.5 \mathrm{mg} / \mathrm{g}$ (phenolic acid: $65.7 \mathrm{mg} / \mathrm{g}$ ). They concluded that the optimal harvest time at which the phenolic compounds reach a maximum level was in mid-September.

Meng et al. [25] differentiated various Perilla frutescens cultivars harvested in China and Japan, compared their polyphenolic compounds, and quantified caffeic, coumaroyl tartaric, and rosmarinic acids, anthocyanin, and flavonoid contents.

Nakamura et al. [45] isolated large amounts of rosmarinic acid from the leaves of Perilla frutescens, var. acuta f. viridis. The antiradical activity of rosmarinic acid was found to be significantly higher than that of vitamin C. These authors concluded that the presence of an orthodihydroxyphenyl group was most important for the scavenging effect.

Nakamura et al. [45] determined the apigenin, caffeic acid, catechin, ferulic acid, luteolin, and rosmarinic acid contents in the leaves and seeds of Perilla frutescens.

Tada et al. [46] isolated various antioxidants (flavones and derivatives of rosmarinic acid, caffeic acid, and coumarin) from the leaves and stems of Perilla frutescens, var. Crispa.

As far as the other parts of the plant are concerned, Lee et al. (2013) investigated the phenolic compound profiles of the methanolic extract of the seeds of fifteen Perilla frutescens cultivars. Nine phenolic compounds were elucidated: caffeic acid and its glucoside, luteolin and apigenin and their glucosides, rosmarinic acid and its glucoside, luteolin, apigenin and their glucosides, and chrysoeriol. The individual and total phenolic contents were remarkably different, especially those of rosmarinic acid and rosmarinic acid-3-O-glucoside, which were the predominant compounds in all the perilla cultivars. The rosmarinic acid-3-O-glucoside and rosmarinic acid contents ranged between 1.02 and $2.42 \mathrm{mg} / \mathrm{g}$ and 1.04 and $2.52 \mathrm{mg} / \mathrm{g}$, respectively. Ha et al. (2012) isolated and identified five phenolic compounds (apigenin, luteolin, caffeic acid3-O-glucoside, rosmarinic acid, and rosmarinic acid-3-Oglucoside) from the seeds of Perilla frutescens. Zhou et al. [47] isolated a total of 11 phenolic compounds (vanillic acid, caffeic acid and its derivatives, rosmarinic acid and its derivatives, apigenin, and luteolin and its glucoside), as well as tryptophan and sucrose, from cold-pressed Perilla frutescens, var. argute, seed flour. 
TABLE 4: Trolox equivalent antioxidant capacity (TEAC) of the perilla extract and fresh matter (FM) at different growth stages.

\begin{tabular}{lccr}
\hline Growth stage & $\begin{array}{c}\text { Plant height } \\
(\mathrm{cm})\end{array}$ & $\begin{array}{c}\text { TEAC } \\
(\text { mmol Trolox eq./g extract })\end{array}$ & $0.379 \pm 0.020^{\mathrm{b}}$ \\
\hline Early vegetative & 15 & $0.308 \pm 0.023^{\mathrm{c}}$ & $0.012 \pm 0.001^{\mathrm{a}}$ \\
Medium vegetative & 30 & $0.451 \pm 0.051^{\mathrm{ab}}$ & $0.007 \pm 0.001^{\mathrm{b}}$ \\
Late vegetative & 40 & $0.507 \pm 0.034^{\mathrm{a}}$ & $0.008 \pm 0.001^{\mathrm{b}}$ \\
Early flowering & 60 & $0.475 \pm 0.057^{\mathrm{ab}}$ & $0.001^{\mathrm{a}}$ \\
Full flowering & 70 & $0.015 \pm 0.002^{\mathrm{a}}$ \\
\hline
\end{tabular}

Means with the same letter in the same column are not significantly different $(P<0.05)$.

TABLE 5: Ferric-reducing antioxidant power (FRAP) of the perilla extract and fresh matter (FM) at different growth stages.

\begin{tabular}{lccc}
\hline Growth stage & $\begin{array}{c}\text { Plant height } \\
(\mathrm{cm})\end{array}$ & $\begin{array}{c}\text { FRAP } \\
\left(\mathrm{mmol} \mathrm{Fe}^{2+} / \mathrm{g} \mathrm{extract}\right)^{\mathrm{a}}\end{array}$ & $1.573 \pm 0.151^{\mathrm{a}}$ \\
\hline Early vegetative & 15 & $0.921 \pm 0.072^{\mathrm{b}}$ & $0.048 \pm 0.005^{\mathrm{a}}$ \\
Medium vegetative & 30 & $1.699 \pm 0.181^{\mathrm{a}}$ & $0.023 \pm 0.002^{\mathrm{c}}$ \\
Late vegetative & 40 & $1.660 \pm 0.114^{\mathrm{a}}$ & $0.037 \pm 0.004^{\mathrm{b}}$ \\
Early flowering & 60 & $1.759 \pm 0.197^{\mathrm{a}}$ & $0.038 \pm 0.003^{\mathrm{b}}$ \\
Full flowering & 70 & & $0.057 \pm 0.006^{\mathrm{a}}$ \\
\hline
\end{tabular}

Means with the same letter in the same column are not significantly different $(P<0.05)$.

3.3. Antioxidant Activity. The TEAC radical scavenging abilities of different perilla growth stages are reported in Table 4. Significant differences can be observed between the stages $(P<0.05)$ for both the extract and for the plant FM, with the highest TEAC value being in the early flowering stage $(0.51 \mathrm{mmol}$ Trolox eq./g of extract) and full flowering stage ( $0.015 \mathrm{mmol}$ Trolox eq./g of FM), respectively.

The FRAP of the perilla extract and of the FM is shown in Table 5 for different growth stages, and the lowest content is found at the medium vegetative stage $\left(0.92 \mathrm{mmol} \mathrm{Fe}{ }^{2+} / \mathrm{g}\right.$ of extract and $0.023 \mathrm{mmol} \mathrm{Fe} \mathrm{F}^{2+} / \mathrm{g}$ of FM, resp.). On the other hand, the highest FRAP content is found at the full flowering stage $\left(1.76 \mathrm{mmol} \mathrm{Fe} \mathrm{m}^{2+} / \mathrm{g}\right.$ of extract and $0.057 \mathrm{mmol} \mathrm{Fe}^{2+} / \mathrm{g}$ of FM, resp.). These results confirm the trend observed for the TEAC assay.

Finally, Figure 3 shows the antiradical activity of perilla extracts against DPPH radicals, expressed as $\mathrm{EC}_{50}$ value, that is, the concentration required to scavenge $50 \%$ of $\mathrm{DPPH}$ radicals. The most active extracts are found in the early vegetative stage $\left(\mathrm{EC}_{50} 34.5 \mu \mathrm{g} / \mathrm{mL}\right.$ ), and these are followed by the early and full flowering stages $\left(\mathrm{EC}_{50} 41.7\right.$ and $42.9 \mu \mathrm{g} / \mathrm{mL}$, resp.).

Jun et al. [42], investigated the antioxidant activities in the leaves of various Perilla frutescens var. acuta extracts, on the basis of the DPPH radical scavenging ability, ABTS radical cation scavenging ability, and reducing power. Samples were extracted with $80 \%$ ethanol and then sequentially fractionated according to the solvent polarity. The highest antioxidant activity was observed for the ethyl acetate fraction. $\mathrm{EC}_{50}$ values of this fraction, for the $\mathrm{DPPH}^{\circ}$ scavenging activity and reducing power, were 2.4 and 1.7 times lower than those of TBHQ, respectively.

Deng et al. [40] determined the antioxidant capacities of lipophilic and hydrophilic extracts of Perilla frutescens leaf and another 55 vegetables. The vegetables with the highest total FRAP values, in decreasing order, were Chinese toon bud $>$ perilla leaf $>$ loosestrife $>$ lotus root $>$ sweet potato leaf, with values of $0.061,0.045,0.025,0.024$, and $0.021 \mathrm{mmol}$ $\mathrm{Fe}^{2+} / \mathrm{g}$, respectively. The vegetables with the highest total TEAC values were ranked as follows: Chinese toon bud > loosestrife $>$ perilla leaf $>$ cowpea $>$ caraway, with values of $0.034,0.025,0.024,0.021$, and $0.018 \mathrm{mmol}$ Trolox/g, respectively.

Zhu et al. [43] successfully separated a rosmarinic acid extract from Perilla frutescens leaves by means of the supramolecular technique and solvent extraction. This extract exhibited antiradical activity against $\mathrm{DPPH}^{\circ}$ of $88.3 \%$, at a concentration of $10 \mu \mathrm{g} / \mathrm{mL}$, while the other subfractions exhibited a scavenging activity below $50 \%$. The antioxidant activity of the total phenolics was $433.9 \mathrm{mg} \mathrm{GAE} / \mathrm{g}$ for the rosmarinic acid extract, $116.9 \mathrm{mg}$ GAE/g for the supernatant, and $170.7 \mathrm{mg} \mathrm{GAE} / \mathrm{g}$ for the supramolecular complex.

In research of Gülçin et al. [29] anthocyanins from Perilla pankinensis were found to be effective on DPPH radical reduction, superoxide anion radical and $\mathrm{H}_{2} \mathrm{O}_{2}$ scavenging, total reducing power, and metal chelating on the ferrous ion activities. Perilla pankinenis, at concentrations of 30 and $45 \mu \mathrm{g} / \mathrm{mL}$, showed strong inhibition of the lipid peroxidation of linoleic acid peroxidation in acid emulsion system.

Li et al. [48] evaluated the antioxidant capacities of infusions of some parts of Perilla frutescens. They found 0.204, 0.039, and 0.028 mmol Fe $\mathrm{Fe}^{2+} / \mathrm{g}$ for FRAP, 0.123, 0.017, and $0.057 \mathrm{mmol}$ Trolox/g for TEAC assays, respectively, in the seeds, stems, and leaves.

Kim et al. [24] investigated the antioxidative activity of various enzymatic extracts from the leaves of Perilla frutescens, var. japonica, by measuring the DPPH, hydroxyl, and alkyl radical scavenging activities. The alcalase and promozyme extracts showed the highest DPPH radical scavenging activities with. $\mathrm{IC}_{50}$ values were 109.7 and $77.3 \mu \mathrm{g} / \mathrm{mL}$, 

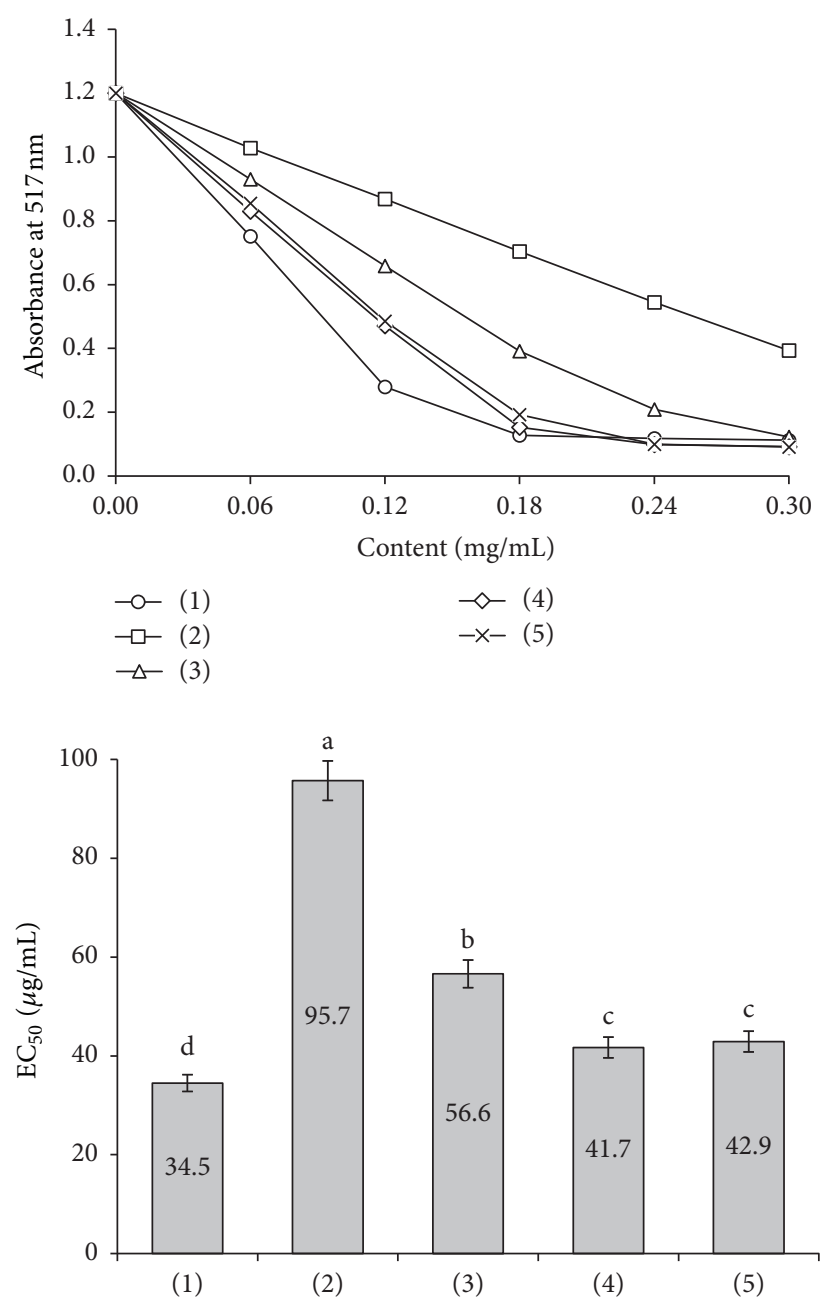

FIGURE 3: Antiradical activity of the extracts against the DPPH radical. (1) early vegetative; (2) medium vegetative; (3) late vegetative; (4) early flowering; (5) full flowering. Means of $\mathrm{EC}_{50}$ with different letters are significantly different $(P<0.05)$.

respectively. All the enzymatic extracts of the leaf scavenged hydroxyl radicals, and the $\mathrm{IC}_{50}$ values of the pepsin and celluclase extracts showed the highest activity at 241.9 and $243.3 \mu \mathrm{g} / \mathrm{mL}$, respectively. The $\alpha$-chymotrypsin extract from the leaves showed the highest scavenging activity, and $\mathrm{IC}_{50}$ value was $33.2 \mu \mathrm{g} / \mathrm{mL}$, while the pepsin extracts showed a protective effect on $\mathrm{H}_{2} \mathrm{O}_{2}$-induced DNA damage and decreased cell death in PC-12 cells induced by hydrogen peroxide. These authors suggested that enzymatic extracts of the leaves can exert an antioxidative effect.

Meng et al. [25] investigated the antioxidant activity of water extracts of some Perilla frutescens cultivars harvested in China and Japan, on the basis of the inhibition of the DPPH free radical. The calculated TEAC value (23-167 $\mu \mathrm{mol} \mathrm{TE} / 100 \mathrm{~mL}$ ) confirmed the high antioxidant activity of these leaf water extracts, due to the amount of total phenolics $(4-29 \mu \mathrm{mol} / 100 \mathrm{~mL})$. These results confirmed the high correlation between antioxidant activity and some $o$ dihydroxylated polyphenolic compounds.
Saita et al. [41] determined the antioxidant activities of green and red varieties of Perilla frutescens, var. crispa and found that the DPPH solutions required 7.9 and $29 \mu \mathrm{g} / \mathrm{mL}$ of red and green perilla, respectively, to scavenge $50 \%$ of DPPH radicals.

As far as the other parts of the plant are concerned, Sargi et al. [49] determined the antioxidant capacity of five seeds: white and brown perilla, chia, golden, and brown flax. The results showed that brown perilla exhibited a stronger antioxidant potential than white perilla and the other seeds. In the DPPH assay, the highest value was found for brown and white perilla (2.54 and $2.38 \mathrm{mmol} \mathrm{TE} / \mathrm{g}$, resp.) and the lowest value for golden flax $(1.16 \mathrm{mmol} \mathrm{TE} / \mathrm{g})$. A similar pattern was found in the FRAP assay, in which brown and white perilla had the highest values $(5.24$ and $4.01 \mathrm{mmol}$ $\mathrm{TE} / \mathrm{g}$, resp.) and golden flax the lowest $(0.33 \mathrm{mmol} \mathrm{TE} / \mathrm{g})$. The highest value in the ABTS assay was also found in the brown perilla seed (4.06 mmol TEAC/g), while white perilla had a value of $3.32 \mathrm{mmol} \mathrm{TE} / \mathrm{g}$. Müller-Waldeck et al. [50] measured the TEAC values of five varieties of Perilla frutescens. The obtained values ranged from 0.032 to $0.056 \mathrm{mmol} \mathrm{TE} / \mathrm{g}$, which are lower than the results reported by Sargi et al. (2013) for white and brown perilla. This difference may be caused by the sample composition as an effect of factors such as climate conditions and geographic location. Lee et al. (2013) investigated the antioxidant properties of an $80 \%$ methanol extract $(50 \mu \mathrm{g} / \mathrm{mL})$ of the seeds of various Perilla frutescens cultivars. All the extracts showed powerful antioxidant activities against DPPH and ABTS radical scavenging activities, with the Yeupsil cultivar exhibiting the highest antioxidant activity ( $83 \%$ and $91 \%$, resp.).

Finally, Tian et al. [51] evaluated the antioxidant potential of different Perilla frutescens oils from 11 areas in China using ABTS, DPPH, and the reducing power. The oils exhibited various degrees of scavenging ability.

\section{Conclusions}

The present results indicate that the antioxidant activity of several components of perilla plant extracts changes during the growth cycle and may be useful in determining the optimal harvest time at which phenolic compounds reach their maximum content. The highest total phenolic compound content was found at the full flowering stage and was related to the rosmarinic acid content. This trend was also confirmed by the TEAC and FRAP values found for the full flowering stage. The highest antiradical activity against $\mathrm{DPPH}^{\circ}$ was observed for the early vegetative stage extract. However, further studies are needed to identify the specific antioxidant components of Perilla frutescens, which may constitute a new functional food and could be an important dietary source for the prevention of diseases caused by oxidative stress.

\section{Conflicts of Interest}

The authors declare that there are no conflicts of interest. 


\section{Authors' Contributions}

Francesco Gai and Pier Giorgio Peiretti designed and performed the biological experiments; Magdalena Karamać and Ryszard Amarowicz designed and performed the chemicals experiments; Francesco Gai, Pier Giorgio Peiretti, Magdalena Karamać, and Ryszard Amarowicz wrote the paper.

\section{Acknowledgments}

The authors would like to express their thanks to the Italian National Research Council which, in the framework of a free exchange program between the Polish Academy of Sciences and the Italian National Research Council, provided a visiting grant to Ryszard Amarowicz.

\section{References}

[1] T. Longvah and Y. G. Deosthale, "Effect of dehulling, cooking and roasting on the protein quality of Perilla frutescens seed," Food Chemistry, vol. 63, no. 4, pp. 519-523, 1998.

[2] M. Asif, "Health effects of omega-3, 6, 9 fatty acids: Perilla frutescens is a good example of plant oils," Oriental Pharmacy \& Experimental Medicine, vol. 11, no. 1, pp. 51-59, 2011.

[3] O. N. Ciftci, R. Przybylski, and M. Rudzińska, "Lipid components of flax, perilla, and chia seeds," European Journal of Lipid Science and Technology, vol. 114, no. 7, pp. 794-800, 2012.

[4] C. M. Da Silva, A. B. Zanqui, A. K. Gohara et al., "Compressed n-propane extraction of lipids and bioactive compounds from Perilla (Perilla frutescens)," Journal of Supercritical Fluids, vol. 102, pp. 1-8, 2015.

[5] S. Oita, T. Kimura, Y. Shibuya, N. Nihei, and K. Tanahashi, "Extraction and digestibility of Perilla frutescens seed proteins," Japan Agricultural Research Quarterly, vol. 42, no. 3, pp. 211-214, 2008.

[6] T. Longvah, Y. G. Deosthale, and P. Uday Kumar, "Nutritional and short term toxicological evaluation of Perilla seed oil," Food Chemistry, vol. 70, no. 1, pp. 13-16, 2000.

[7] M. Yamada, S. Kanazawa, K. Yamada, and Y. Yamauti, "Effect of perilla seeds fed term on the fatty acids composition in the muscle and lipid tissue of pig," Nihon Yoton Gakkaishi, vol. 38, no. 3, pp. 130-134, 2001.

[8] P. G. Peiretti, L. Gasco, A. Brugiapaglia, and F. Gai, "Effects of perilla (Perilla frutescens L.) seeds supplementation on performance, carcass characteristics, meat quality and fatty acid composition of rabbits," Livestock Science, vol. 138, no. 1-3, pp. 118-124, 2011.

[9] T. J. Ha, J. H. Lee, M.-H. Lee et al., "Isolation and identification of phenolic compounds from the seeds of Perilla frutescens (L.) and their inhibitory activities against $\alpha$-glucosidase and aldose reductase," Food Chemistry, vol. 135, no. 3, pp. 1397-1403, 2012.

[10] Z. Guan, S. Li, Z. Lin et al., "Identification and quantitation of phenolic compounds from the seed and pomace of Perilla frutescens using HPLC/PDA and HPLC-ESI/QTOF/MS/MS," Phytochemical Analysis, vol. 25, no. 6, pp. 508-513, 2014.

[11] R. K. Bachheti, A. Joshi, and T. Ahmed, "A phytopharmacological overview on Perilla frutescens," International Journal of Pharmaceutical Sciences Review and Research, vol. 26, no. 2, pp. 55-61, 2014.

[12] N. Banno, T. Akihisa, H. Tokuda et al., "Triterpene acids from the leaves of Perilla frutescens and their anti-inflammatory and antitumor-promoting effects," Bioscience, Biotechnology and Biochemistry, vol. 68, no. 1, pp. 85-90, 2004.

[13] S. Buchwald-Werner, H. Fujii, C. Schön, and C. Doebis, "Investigation of a Perilla frutescens special extract: anti-inflammatory and immune-modulatory properties," Agro Food Industry HiTech, vol. 23, no. 5, pp. 38-41, 2012.

[14] L.-J. Feng, C.-H. Yu, K.-J. Ying, J. Hua, and X.-Y. Dai, "Hypolipidemic and antioxidant effects of total flavonoids of Perilla Frutescens leaves in hyperlipidemia rats induced by high-fat diet," Food Research International, vol. 44, no. 1, pp. 404-409, 2011.

[15] L.-N. Huo, W. Wang, C.-Y. Zhang et al., "Bioassay-guided isolation and identification of xanthine oxidase inhibitory constituents from the leaves of Perilla frutescens," Molecules, vol. 20, no. 10, pp. 17848-17859, 2015.

[16] J.-H. Liu, A. Steigel, E. Reininger, and R. Bauer, "Two new prenylated 3-benzoxepin derivatives as cyclooxygenase inhibitors from Perilla frutescens var. acuta," Journal of Natural Products, vol. 63, no. 3, pp. 403-405, 2000.

[17] H. Ueda and M. Yamazaki, "Anti-inflammatory and antiallergic actions by oral administration of a perilla leaf extract in mice," Bioscience, Biotechnology and Biochemistry, vol. 65, no. 7, pp. 1673-1675, 2001.

[18] H. Ueda, C. Yamazaki, and M. Yamazaki, "Luteolin as an antiinflammatory and anti-allergic constituent of Perilla frutescens," Biological and Pharmaceutical Bulletin, vol. 25, no. 9, pp. 1197$1202,2002$.

[19] H. Ueda, C. Yamazaki, and M. Yamazaki, "Inhibitory effect of perilla leaf extract and luteolin on mouse skin tumor promotion," Biological and Pharmaceutical Bulletin, vol. 26, no. 4, pp. 560-563, 2003.

[20] G. Žekonis, J. Žekonis, R. Šadzevičiene, G. Šimoniene, and E. Kevelaitis, "Effect of Perilla frutescens aqueous extract on free radical production by human neutrophil leukocytes," Medicina, vol. 44, no. 9, pp. 699-705, 2008.

[21] I. M. Chung, S. J. Yun, J. T. Kim, J. G. Gwag, J. D. Sung, and H. S. Suh, "Test of superoxide dismutase characteristics and antioxidant activity in perilla leaves," Korean Journal of Crop Science, vol. 40, no. 4, pp. 504-511, 1995.

[22] J. H. Lee, K. H. Park, M.-H. Lee et al., "Identification, characterisation, and quantification of phenolic compounds in the antioxidant activity-containing fraction from the seeds of Korean perilla (Perilla frutescens) cultivars," Food Chemistry, vol. 136, no. 2, pp. 843-852, 2013.

[23] E. Lin, H. Chou, P. Kuo, and Y. Huang, "Antioxidant and antiproliferative activities of methanolic extracts of Perilla frutescens," Journal of Medicinal Plants Research, vol. 4, no. 6, pp. 477-483, 2010.

[24] E.-K. Kim, S.-J. Lee, O. L. Beong et al., "Antioxidative and neuroprotective effects of enzymatic extracts from leaves of Perilla frutescens var. japonica," Food Science and Biotechnology, vol. 17, no. 2, pp. 279-286, 2008.

[25] L. Meng, Y. F. Lozano, E. M. Gaydou, and B. Li, “Antioxidant activities of polyphenols extracted from Perilla frutescens varieties," Molecules, vol. 14, no. 1, pp. 133-140, 2009.

[26] T. Nakazawa and K. Ohsawa, "Metabolites of orally administered Perilla frutescens extract in rats and humans," Biological and Pharmaceutical Bulletin, vol. 23, no. 1, pp. 122-127, 2000.

[27] E. Hong, K. H. Park, and G.-H. Kim, "Phenolic-enriched fractions from Perilla frutescens var. Acuta: determinating rosmarinic acid and antioxidant activity," Journal of Food Biochemistry, vol. 35, no. 6, pp. 1637-1645, 2011. 
[28] Y. H. Lee, B. Kim, S. Kim et al., "Characterization of metabolite profiles from the leaves of green perilla (Perilla frutescens) by ultra high performance liquid chromatography coupled with electrospray ionization quadrupole time-of-flight mass spectrometry and screening for their antioxidant properties," Journal of Food and Drug Analysis, In press.

[29] I. Gülçin, D. Berashvili, and A. Gepdiremen, "Antiradical and antioxidant activity of total anthocyanins from Perilla pankinensis decne," Journal of Ethnopharmacology, vol. 101, no. 1-3, pp. 287-293, 2005.

[30] V. Povilaityte and P. R. Venskutonis, "Antioxidative activity of purple peril (Perilla frutescens L.), Moldavian dragonhead (Dracocephalum moldavica L.), and Roman chamomile (Anthemis nobilis L.) extracts in rapeseed oil," JAOCS, Journal of the American Oil Chemists' Society, vol. 77, no. 9, pp. 951-956, 2000.

[31] M. Skowyra, V. Falguera, N. Azman, F. Segovia, and M. Almajano, "The effect of Perilla frutescens extract on the oxidative stability of model food emulsions," Antioxidants, vol. 3, no. 1, pp. 38-54, 2014.

[32] H.-J. Chou, J.-T. Kuo, and E.-S. Lin, "Comparative antioxidant properties of water extracts from different parts of beefsteak plant (Perilla frutescens)," Journal of Food and Drug Analysis, vol. 17, no. 6, pp. 489-496, 2009.

[33] P. G. Peiretti, "Fatty acid content and chemical composition of vegetative parts of perilla (Perilla Frutescens L.) after different growth lengths," Research Journal of Medicinal Plant, vol. 5, no. 1, pp. 72-78, 2011.

[34] R. Amarowicz and B. Raab, "Antioxidant activity of leguminous seed extracts evaluated by chemiluminescencje methods," Zeitschrift für Natuforschunng, vol. C52, pp. 709-712, 1997.

[35] H. H. Orak, M. Karamac, R. Amarowicz, and M. Karamać, "Antioxidant activity of phenolic compounds of red bean (Phaseolus vulgaris L)," Oxidation Communications, vol. 38, no. 1, pp. 67-76, 2015.

[36] R. Re, N. Pellegrini, A. Proteggente, A. Pannala, M. Yang, and C. Rice-Evans, "Antioxidant activity applying an improved ABTS radical cation decolorization assay," Free Radical Biology \& Medicine, vol. 26, no. 9-10, pp. 1231-1237, 1999.

[37] I. F. F. Benzie and J. J. Strain, "Ferric reducing/antioxidant power assay: direct measure of total antioxidant activity of biological fluids and modified version for simultaneous measurement of total antioxidant power and ascorbic acid concentration," Methods in Enzymology, vol. 299, pp. 15-27, 1999.

[38] R. Amarowicz, I. Estrella, T. Hernández, and A. Troszyńska, "Antioxidant activity of extract of adzuki bean and its fractions," Journal of Food Lipids, vol. 15, no. 1, pp. 119-136, 2008.

[39] P. G. Peiretti, G. Meineri, F. Gai, E. Longato, and R. Amarowicz, "Antioxidative activities and phenolic compounds of pumpkin (Cucurbita pepo) seeds and amaranth (Amaranthus caudatus) grain extracts," Natural Product Research, In press.

[40] G.-F. Deng, X. Lin, X.-R. Xu, L.-L. Gao, J.-F. Xie, and H.-B. $\mathrm{Li}$, "Antioxidant capacities and total phenolic contents of 56 vegetables," Journal of Functional Foods, vol. 5, no. 1, pp. 260266, 2013.

[41] E. Saita, Y. Kishimoto, M. Tani et al., "Antioxidant activities of Perilla frutescens against low-density lipoprotein oxidation in vitro and in human subjects," Journal of Oleo Science, vol. 61, no. 3, pp. 113-120, 2012.

[42] H.-I. Jun, B.-T. Kim, G.-S. Song, and Y.-S. Kim, "Structural characterization of phenolic antioxidants from purple perilla (Perilla frutescens var. acuta) leaves," Food Chemistry, vol. 148, pp. 367-372, 2014.
[43] F. Zhu, T. Asada, A. Sato, Y. Koi, H. Nishiwaki, and H. Tamura, "Rosmarinic acid extract for antioxidant, antiallergic, and $\alpha$ glucosidase inhibitory activities, isolated by supramolecular technique and solvent extraction from Perilla leaves," Journal of Agricultural and Food Chemistry, vol. 62, no. 4, pp. 885-892, 2014.

[44] N. S. Kang and J. H. Lee, "Characterisation of phenolic phytochemicals and quality changes related to the harvest times from the leaves of Korean purple perilla (Perilla frutescens)," Food Chemistry, vol. 124, no. 2, pp. 556-562, 2011.

[45] Y. Nakamura, Y. Ohto, A. Murakami, and H. Ohigashi, "Superoxide scavenging activity of rosmarinic acid from Perilla frutescens Britton Var. acuta $f$. viridis," Journal of Agricultural and Food Chemistry, vol. 46, no. 11, pp. 4545-4550, 1998.

[46] M. Tada, R. Matsumoto, H. Yamaguchi, and K. Chiba, "Novel Antioxidants Isolated from Perilla frutescens Britton var. crispa (Thunb.)," Bioscience, Biotechnology and Biochemistry, vol. 60, no. 7, pp. 1093-1095, 1996.

[47] X.-J. Zhou, L.-L. Yan, P.-P. Yin et al., "Structural characterisation and antioxidant activity evaluation of phenolic compounds from cold-pressed Perilla frutescens var. arguta seed flour," Food Chemistry, vol. 164, pp. 150-157, 2014.

[48] S. Li, S.-K. Li, R.-Y. Gan, F.-L. Song, L. Kuang, and H.-B. Li, "Antioxidant capacities and total phenolic contents of infusions from 223 medicinal plants," Industrial Crops and Products, vol. 51, pp. 289-298, 2013.

[49] S. C. Sargi, B. C. Silva, H. M. C. Santos et al., "Antioxidant capacity and chemical composition in seeds rich in omega-3: Chia, flax, and perilla," Food Science and Technology, vol. 33, no. 3, pp. 541-548, 2013.

[50] F. Müller-Waldeck, J. Sitzmann, W. H. Schnitzler, and J. Graßmann, "Determination of toxic perilla ketone, secondary plant metabolites and antioxidative capacity in five Perilla frutescens L. varieties," Food and Chemical Toxicology, vol. 48, no. 1, pp. 264-270, 2010.

[51] J. Tian, X. Zeng, S. Zhang et al., "Regional variation in components and antioxidant and antifungal activities of Perilla frutescens essential oils in China," Industrial Crops and Products, vol. 59, pp. 69-79, 2014. 

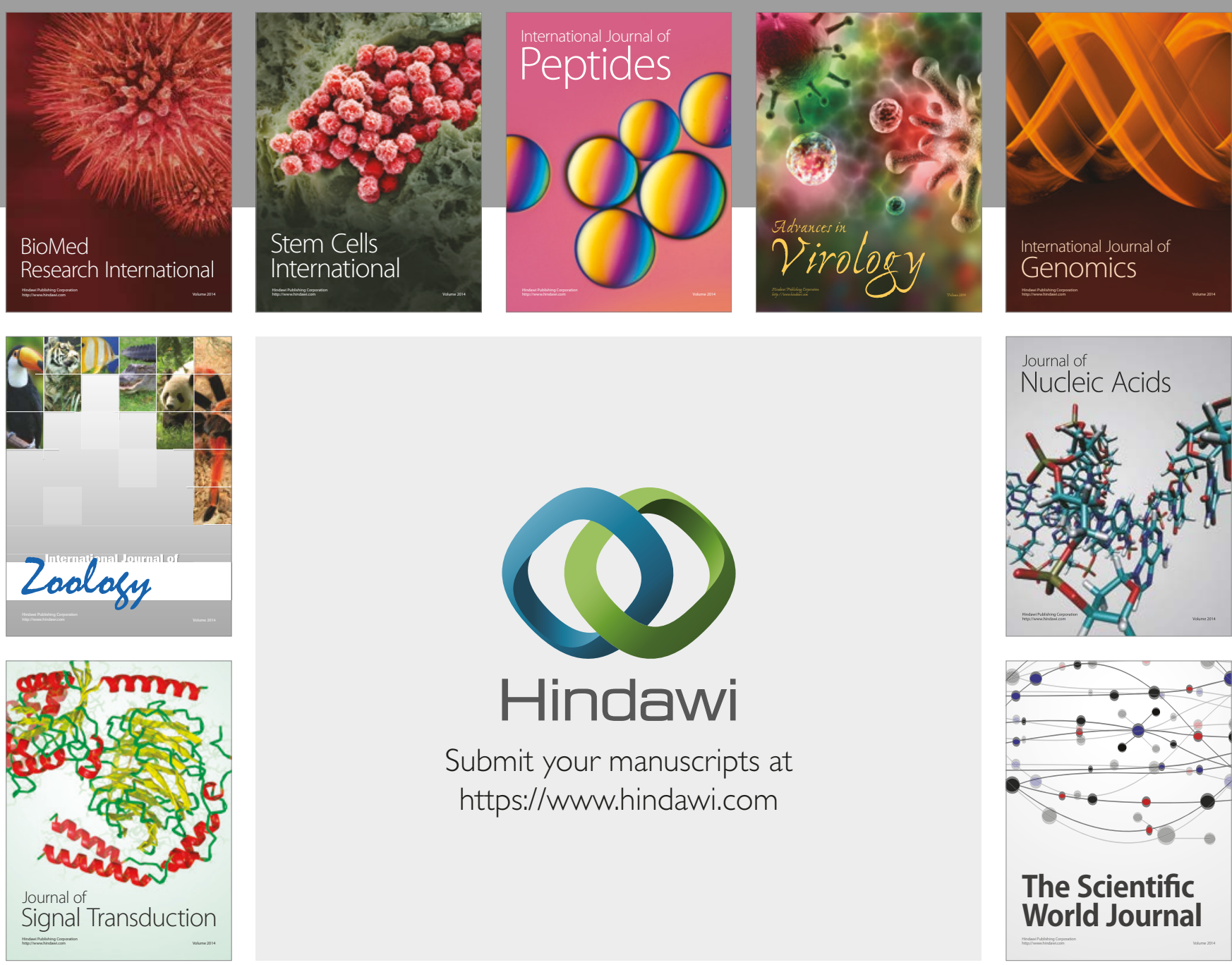

Submit your manuscripts at

https://www.hindawi.com
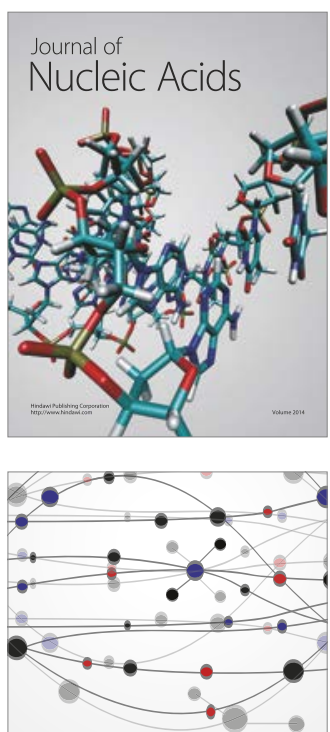

The Scientific World Journal

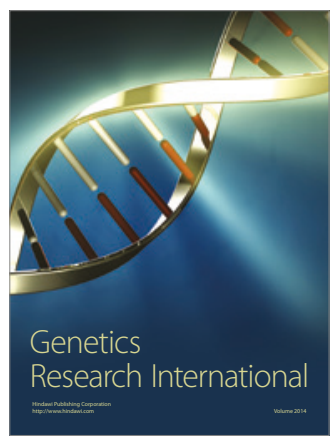

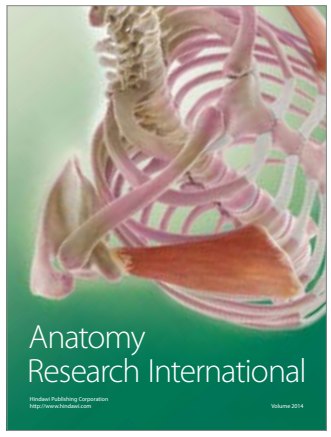

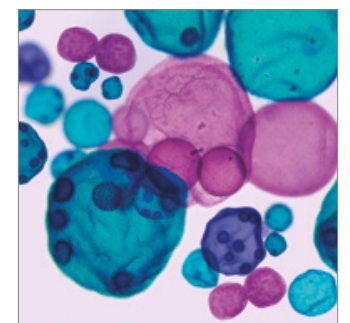

International Journal of Microbiology
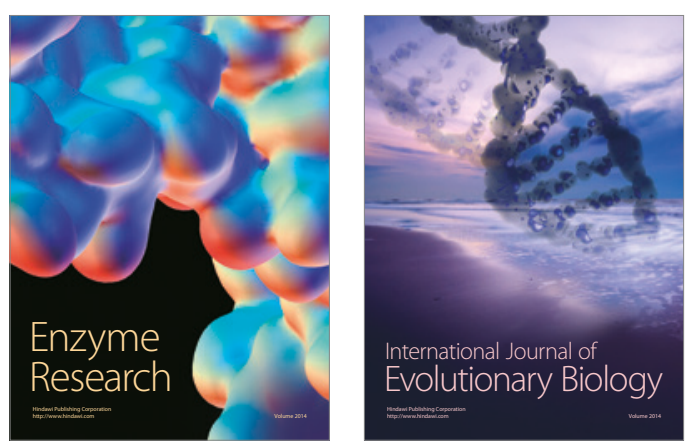
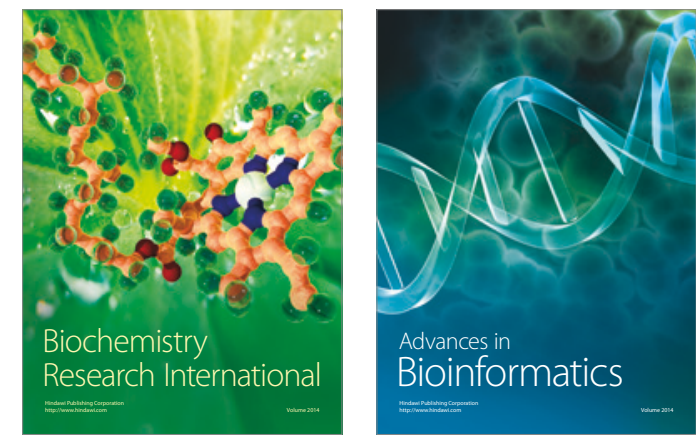

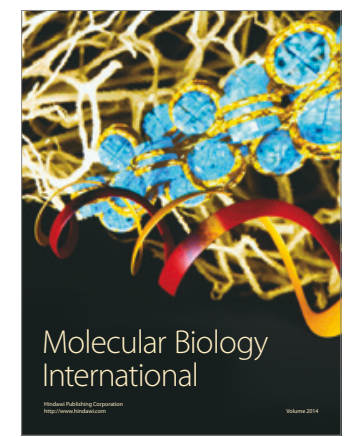

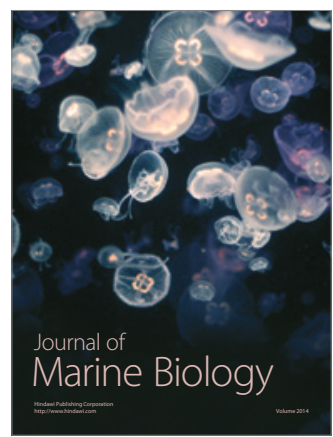

